D.O.I.: $10.3895 / \mathrm{S} 1808-04482010000100012$

\title{
A LIDERANÇA TRANSFORMACIONAL COMO FACTOR DE DESENVOLVIMENTO NA GESTÃO PELA QUALIDADE TOTAL: CRIATIVIDADE, INOVAÇÃO, CONFIANÇA E TRABALHO EM EQUIPA
}

\author{
TRANSFORMATIONAL LEADERSHIP AS A FACTOR IN THE \\ DEVELOPMENT TOTAL QUALITY MANAGEMENT: CREATIVITY, \\ INNOVATION, TRUST AND TEAMWORK
}

\author{
Rui Correia ${ }^{1}$; Emerson Wagner Mainardes ${ }^{2}$; Luis Lourenço ${ }^{3}$ \\ ${ }^{1}$ Universidade da Beira Interior - UBI - Covilhã - Portugal \\ rfcorreira.sa@gmail.com \\ ${ }^{2} \mathrm{NECE}$ - Universidade da Beira Interior - UBI - Covilhã - Portugal \\ emerson.wm@sapo.pt \\ ${ }^{3} \mathrm{NECE}$ - Universidade da Beira Interior - UBI - Covilhã - Portugal \\ lourenco@ubi.pt
}

\begin{abstract}
Resumo
Diversos estudos de investigação têm conduzido à identificação da liderança como um potencial catalisador da gestão pela qualidade total. Além disso, estudos empíricos têm demonstrado, de forma consistente, uma relação positiva e significante entre a liderança transformacional $e$ indicadores de eficiência no trabalho. Um sistema estruturado de liderança deve basear-se em valores claros e em princípios organizacionais que sustentem os processos de tomada de decisão e permitam orientar e inspirar a organização, comprometendo todos os seus colaboradores, na senda de padrões de excelência. Assim, e para que se promova uma cultura de excelência orientada para a qualidade total, é necessária uma forte concertação e convergência das práticas de gestão entre todos os actores organizacionais. Neste contexto, é fundamental que a direcção de topo da organização estabeleça um conjunto de valores e princípios organizacionais capazes de estabelecer um rumo a seguir, e balizem o comportamento dos seus membros, orientando a acção organizacional para elevados padrões de qualidade. Entre os investigadores e especialistas, é unânime reconhecer que cabe à direcção de topo liderar o movimento pela qualidade. Neste sentido, é expectável que os líderes definam a missão e a estratégia organizacional, estabeleçam valores e princípios de gestão inspiradores das melhores práticas de gestão orientadas para a qualidade total. Este trabalho explora a relação conceptual entre a liderança transformacional e a gestão pela qualidade total - ao nível das dimensões da inovação, criatividade, confiança $e$ trabalho em equipa - apresentando proposições iniciais que podem nortear futuras investigações dentro desta área de conhecimento.
\end{abstract}

Palavras-chave: gestão pela qualidade total; liderança transformacional; criatividade; inovação; confiança. 


\section{Introdução}

O desenvolvimento e a maturação da gestão pela qualidade condicionaram esta área da gestão a ultrapassar o seu domínio industrial inicial, conduzindo-a a adquirir proeminência em todos os sectores de actividade, incluindo os sectores industrial e de serviços, públicos e privados. A qualidade conquistou o estatuto de campo teórico apetecível para a comunidade académica, o que gerou esforços significativos para a expansão e refinamento das suas bases teóricas (SCHROEDER; LINDERMAN; ZHANG, 2005).

O desenvolvimento de sistemas, organizações e associações para a garantia da qualidade, assim como a instituição de modelos e prémios de excelência (EASTON, 1993; CORRIGAN, 1994; CARAVATTA, 1997; TONK, 2000; VOKURKA; STANDING; BRAZEAL, 2000), são alguns dos reflexos mais paradigmáticos do movimento mundial em favor da qualidade. Os prémios galardoam determinadas práticas organizacionais, mas também têm o propósito de sugerir processos de melhoria e excelência. Estes modelos e prémios de excelência (designadamente os europeu, americano, canadiano, japonês e australiano) colocam o critério da liderança em lugar de destaque (VOKURKA; STANDING; BRAZEAL, 2000).

As expectativas projectadas sobre os líderes permitem-lhes exercer verdadeiros efeitos sobre a organização. Se as pessoas consideram que o líder é capaz de mudar o rumo dos acontecimentos,

é provável que acatem as suas ordens e decisões de modo empenhado, contribuindo para que se alcance aquilo que espera conseguir. Pelo contrário, se consideram que o líder é incompetente e incapaz, é provável que atenuem esforços e o seu empenho, e não encarem a acção do líder com entusiasmo (ROSENTHAL; JACOBSON, 1968; LIVINGSTON, 1969; PFEFFER, 1994; EDEN et al., 2000; WHITE; LOCKE, 2000).

A European Foundation for Quality Management (EFQM) releva esta dimensão ao enunciar que as organizações excelentes têm líderes que definem e comunicam uma visão clara para as suas organizações. Deste modo, associam e motivam outros líderes a inspirar os seus colaboradores. A Figura 1, respeitante ao modelo europeu, é elucidativa, não só porque denota a relação presumida entre liderança e qualidade, mas também porque procura explicar os seus efeitos mais gerais sobre o desempenho organizacional.

Esta premissa é extensiva aos restantes modelos/prémios. O modelo baseia-se na relação entre critérios facilitadores e os resultados, numa procura de causalidades. Existe uma relação dinâmica entre os facilitadores e os resultados, uma vez que a excelência nos facilitadores será projectada nos resultados. O prémio avalia a forma como a satisfação das pessoas e do consumidor, bem como o impacto na sociedade, estão a ser conseguidos através da liderança conduzindo os 
facilitadores, tais como a gestão de recursos humanos, política e estratégia, recursos e processos tendentes a alcançar a excelência nos resultados (ANTÓNIO; TEIXEIRA, 2007).

Figura 1 - O modelo de excelência da European Foundation for Quality Management

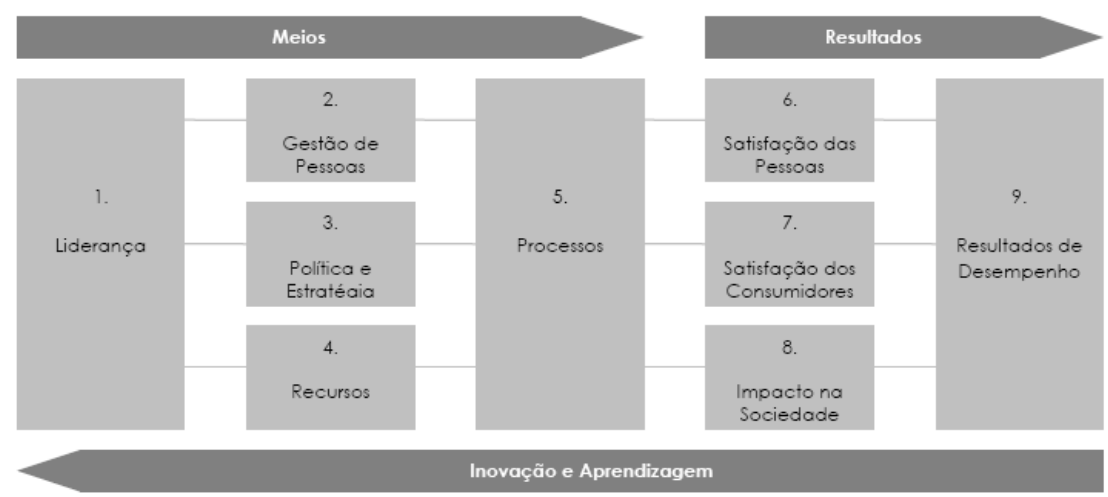

Fonte: Adaptado de Cunha et al (2007, p. 340)

Esta presumível influência foi sublinhada por Deming (1986) e Juran (1989). Por outro lado, esta dimensão tem sido reconhecida por vários académicos, através do desenvolvimento de modelos teóricos e de trabalhos empíricos. Waldman (1993) presume que a liderança transformacional influência as políticas e comportamentos de gestão pela qualidade total - melhoria contínua, trabalho de equipa e perspectiva sistémica - tanto pela via directa como através da cultura organizacional - Figura 2. Este autor chama a atenção para a importância da liderança persistente, isto é, dos esforços continuados dos líderes em direcção à qualidade.

Figura 2 - O modelo que estabelece o nexo entre a liderança e a Gestão pela Qualidade Total (GQT)

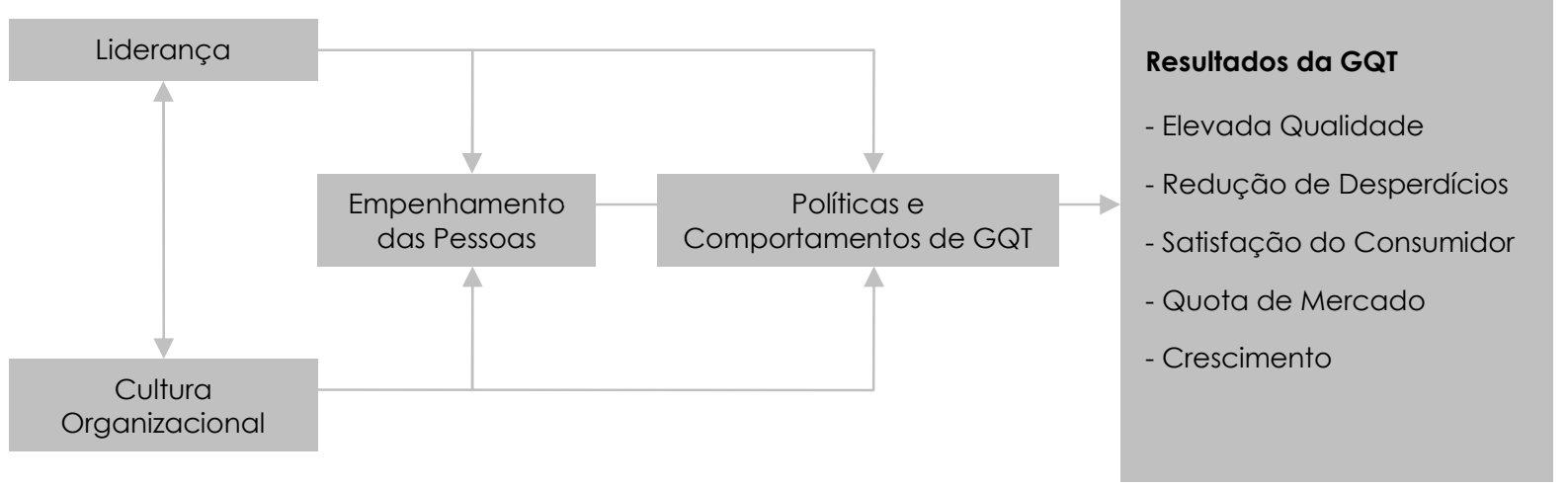

Fonte: Adaptado de Waldman (1993, p. 66)

Pelo exposto, o presente trabalho visa explorar as fundações teóricas da qualidade total, procurando compreender de que forma o estilo de liderança transformacional pode gerar impactes positivos no modelo de gestão pela qualidade total. Neste contexto, importa compreender qual o contributo das práticas de liderança transformacional para a dinamização da gestão pela qualidade 
total. Académicos, investigadores, gestores e consultores têm vindo, sobretudo ao longo dos últimos anos, a desenvolver ou a dar o seu contributo para a criação de novos conceitos, quadros conceptuais de referência e metodologias no campo da liderança transformacional. Mas como avaliar o contributo das práticas de liderança transformacional para a qualidade total? A liderança transformacional será um estilo de liderança capaz de catalizar e incrementar a dinâmica dos processos de gestão pela qualidade total?

Procurarou-se responder a estas e a outras questões, sobre a relevância da liderança transformacional para a gestão pela qualidade total ao longo do texto, onde foram abordados os aspectos a seguir.

Nos pontos 2 e 3, exploram-se as diferentes perspectivas do conceito de qualidade e caracteriza-se o conceito de gestão pela qualidade total, respectivamente. Em seguida, no ponto 4, caracteriza-se a liderança transformacional procurando precisar o conceito. São ainda caracterizados os líderes autenticamente transformacionais, por evidenciarem a relevância do referencial ético e moral, como um factor determinante na liderança transformacional. No ponto 5, propõe-se um modelo que foca quatro das principais dimensões desenvolvidas através do exercício de um estilo de liderança transformacional, e que contribuem para o alcance de resultados de excelência através de práticas de gestão pela qualidade total: 1) criatividade; 2) inovação; 3) confiança; e, 4) trabalho em equipa.

São apresentadas proposições como princípios de investigação, procurando estabelecer relações sinérgicas entre o estilo de liderança transformacional e o modelo de gestão pela qualidade total. A seguir, no ponto 6 , refere-se a liderança transformacional como um elemento central para alavancar uma organização para a qualidade total. Por último, nas considerações finais, é reforçada a convicção de que é possível melhorar a performance das organizações orientadas para a qualidade total, através da acção dos líderes transformacionais. São igualmente mencionados limites ao presente trabalho, bem como propostas futuras linhas de investigação.

\section{Perspectivas sobre o conceito de qualidade}

Sem uma análise prévia ao conceito de qualidade não se compreenderia bem o processo necessário à sua gestão. A discussão em torno da melhor definição para o conceito de qualidade tem sido muito acesa e contínua, e tem vindo a merecer uma grande atenção e interesse. O termo qualidade é uma das palavras mais utilizadas pelos gestores e executivos de organizações contemporâneas. O conceito experimentou muitas alterações e significados ao longo do tempo, tantos quanto o número de fenómenos que pretendia descrever. Assim, e atendendo à multiplicidade 
dos fenómenos e das variáveis em estudo, são utilizados diferentes conceitos de qualidade em função da natureza do fenómeno que se pretende descrever e/ou explicar.

No entanto, é possível resumir a evolução do conceito, em função das suas diferentes perspectivas. Através da análise ao trabalho de Reeves e Bednar (1994), foi possível resumir a ampla terminologia sobre qualidade e sistematizar os diferentes conceitos em função de quatro perspectivas clássicas referidas pela literatura. Estas abordagens apresentam-se de forma resumida no Quadro 1.

Quadro 1 - Perspectivas sobre o conceito de qualidade

\begin{tabular}{|c|c|}
\hline Perspectiva & Conceitos/Fundamentos \\
\hline Excelência & $\begin{array}{l}\text { A qualidade é universal e absolutamente reconhecível, escapando a definições e a medições precisas. } \\
\text { A qualidade é encarada como algo, que não se define. Está-se para além de uma definição. Está-se } \\
\text { perante uma experiência directa que pode ser entendida apenas por aqueles que se expõem ou são } \\
\text { expostos, a um conjunto de objectos que evidenciam as suas características. A qualidade é um } \\
\text { fenómeno incorporado, não podendo ser entendida apenas em função da cognição. A qualidade faz } \\
\text { ressaltar nos indivíduos, não apenas uma resposta racional mas também emoções e sentimentos como } \\
\text { prazer, dor, ódio e felicidade. A qualidade como excelência é um instrumento de orientação apontado } \\
\text { para um estado desejado. Iniciaram esta discussão, filósofos como Sócrates, Platão e Aristóteles, } \\
\text { entre outros filósofos gregos. Reeves e Bednar (1994) referem que partilharam desta perspectiva, } \\
\text { autores como Kitto em 1951, Pirsig em } 1974 \text { e 1992, e Tuchman em 1980. }\end{array}$ \\
\hline Valor -Preço & $\begin{array}{l}\text { A aplicação da definição de qualidade como excelência, no que respeita ao comércio, foi posta em } \\
\text { questão em meados do século XVIII, quando os comerciantes ocidentais quiseram alcançar um } \\
\text { mercado mais vasto para as mercadorias a transaccionar. A abordagem do valor considera a qualidade } \\
\text { como sendo o grau de excelência a um preço aceitável ou o controlo da variabilidade a um custo } \\
\text { aceitável. De acordo com Abbott, em } 1955 \text {, a qualidade e preço estão inextrincavelmente ligados na } \\
\text { escolha económica. No entanto, há pouca concordância na literatura quanto ao facto da relação entre } \\
\text { qualidade e custo ser directa ou inversa. É largamente aceite que os preços afectam a percepção que } \\
\text { as pessoas têm sobre a qualidade mas não existem modelos que tenham em conta a complexidade } \\
\text { introduzida nesta relação. A abordagem baseada no valor tenta relacionar os conceitos de qualidade e } \\
\text { preço, tendo como resultado um conceito híbrido de excelência alcançável. Esta noção não possui } \\
\text { fronteiras definidas e é muitas vezes altamente subjectiva. No mercado, as decisões de consumo são } \\
\text { baseadas no preço e na qualidade. A abordagem de valor tenta estabelecer uma relação entre estes } \\
\text { dois aspectos. O consumidor é certamente quem mais beneficia do acesso a produtos que têm um } \\
\text { maior valor em relação ao preço dispendido. As empresas tendem a anunciar os seus produtos como } \\
\text { oferecendo tanto valor como qualidade (value for money). Neste âmbito, são citados por Reeves e } \\
\text { Bednar (1994) autores como Feigenbaum em 1951, Johnson em } 1988 \text { e Abbott em } 1995 \text {. }\end{array}$ \\
\hline $\begin{array}{l}\text { Conformidade } \\
\text { com os } \\
\text { Requisitos }\end{array}$ & $\begin{array}{l}\text { Esta abordagem baseada na produção, define a qualidade como o grau de conformidade de um } \\
\text { produto com a sua concepção ou especificação. Crosby em } 1979 \text { define a qualidade como } \\
\text { conformidade com os requisitos. A variação no processo e na concepção do produto é encarada como } \\
\text { sendo uma ameaça constante para que se consiga atingir a conformidade com os requisitos. Para } \\
\text { alguns autores, a variação pode ser totalmente eliminada, para outros, só é possível controlar um certo } \\
\text { tipo de variação. No entanto, ambos concordam que, caso a concepção e o processo de produção } \\
\text { fossem perfeitamente estáveis e fiáveis, a qualidade estaria necessariamente presente. Para conseguir } \\
\text { consistência na concepção, as empresas podem assumir que qualquer desvio em relação ao requisito, } \\
\text { aumenta o custo final do produto, incluindo a garantia e perda de reconhecimento do consumidor. Na } \\
\text { fase de produção, o controlo de produção permite aos trabalhadores distinguir entre erros evitáveis e } \\
\text { os que não podem ser evitados, bem como identificar as suas causas prováveis. Esta abordagem tem } \\
\text { uma vertente de engenharia, tendo por base a aplicação de métodos estatísticos ao controlo da } \\
\text { variação na concepção, quer nos processos produtivos quer nos produtos finais. A maior parte dos } \\
\text { avanços técnicos na qualidade são devidos à standardização e produção em massa. Enquanto a } \\
\text { standardização trouxe benefícios aos gestores, accionistas e em grande escala aos consumidores, os } \\
\text { trabalhadores foram reduzidos a meras extensões de ferramentas e máquinas. O regime de produção } \\
\text { em massa conduziu à redução das capacidades de trabalho e a uma redução do papel desempenhado } \\
\text { pelos trabalhadores. Convém notar que a tomada de todos os passos necessários para assegurar a } \\
\text { conformidade do produto com as suas especificações internas não conduz necessariamente à } \\
\text { satisfação do consumidor. Para este, a qualidade de um produto constitui uma percepção subjectiva, e }\end{array}$ \\
\hline
\end{tabular}




\begin{tabular}{|c|c|}
\hline & $\begin{array}{l}\text { a conformidade com as especificações desempenha, muitas vezes, um papel menor na influência } \\
\text { sobre tais percepções. } \\
\text { Após } 1930 \text {, muitas indústrias procuraram reduzir o custo associado às acções de controlo para medir a } \\
\text { conformidade. Reeves e Bednar (1994) referem que este conceito de qualidade, nasceu nos anos } 30 \\
\text { do século passado com o Controlo Estatístico de Qualidade, cujo início se deve aos gráficos de } \\
\text { controlo inventados por Shewhart em 1931, da Bell Laboratories. As suas investigações acerca da } \\
\text { variabilidade dos materiais foram a génese do conceito de Controlo Estatístico dos Processos (SPC - } \\
\text { Statistical Process Control). Em 1951, Juran edita o livro "Quality Control Handbook", separando a } \\
\text { qualidade em dois componentes: qualidade de design e qualidade de conformidade. A qualidade de } \\
\text { design relaciona-se com a adequação. A qualidade de conformidade, por sua vez, está relacionada } \\
\text { com a necessidade de perceber até que ponto o produto está conforme os requisitos. }\end{array}$ \\
\hline $\begin{array}{c}\text { Satisfazer } \\
\text { e/ou Exceder } \\
\text { as } \\
\text { Expectativas } \\
\text { dos Clientes }\end{array}$ & $\begin{array}{l}\text { Nesta perspectiva a qualidade é tipicamente definida como satisfazer ou exceder as expectativas dos } \\
\text { consumidores. Embora o ímpeto para tal conceptualização provenha da literatura do marketing dos } \\
\text { serviços, alguns autores da área da qualidade salientam também a importância do utilizador final. A } \\
\text { crescente importância do sector dos serviços na economia, condicionou alterações na abordagem } \\
\text { promovida pelos principais autores, quando estes procuravam definir o conceito de qualidade. Já na } \\
\text { década de } 1950 \text {, Feigenbaum definia qualidade como o grau de satisfação das expectativas do cliente } \\
\text { proporcionado pelo produto ou serviço. Da mesma forma, Juran e outros, em } 1974 \text { associavam a } \\
\text { qualidade ao grau de satisfação dos objectivos, proporcionado pelo produto ao utilizador. Juran } \\
\text { alargou o conceito de cliente, passando a considerar as necessidades do cliente interno, considerando } \\
\text { que também deveriam ser satisfeitas. Para Zeitham, Parasuraman e Berry, em 1990, só os clientes } \\
\text { podem avaliar a qualidade, qualquer outra avaliação é irrelevante. Qualidade é aquilo que o cliente } \\
\text { afirma que é, e a qualidade de um produto ou serviço é aquilo que o cliente percepciona que é, } \\
\text { conforme disseram Buzzell e Gale em 1987. No entanto, esta definição baseada no utilizador favorece } \\
\text { o cliente mas coloca desafios importantes aos gestores, que precisam de interpretar as percepções } \\
\text { subjectivas dos clientes e em seguida gerar eficiência operacional. }\end{array}$ \\
\hline
\end{tabular}

Fonte: Adaptado de Reeves e Bednar (1994)

A identificação da excelência é difícil, o mesmo acontecendo à sua medição, para além de ser problemático torná-la controlável. A definição de qualidade afastou-se da excelência, em direcção à conformidade com os requisitos e mais tarde com o valor do dinheiro e satisfação do consumidor.

O presente trabalho valoriza de igual forma os diferentes conceitos de qualidade apresentados. No entanto, importa reconhecer que quando é focado o conceito de qualidade total, a abordagem centra-se na cultura de empresa capaz de assegurar a satisfação e/ou exceder as expectativas dos clientes (PIRES, 2007).

\section{Gestão pela qualidade total}

A gestão pela qualidade total evoluiu com o próprio conceito de qualidade, entendendo a qualidade como uma oportunidade para competir. Actualmente, a definição mais abrangente de qualidade incorpora noções de melhor preço, ausência de defeitos, cumprimento do projecto, adequação ao uso e satisfação dos clientes através da melhoria contínua nos produtos e serviços oferecidos. Controlo total de qualidade, gestão pela qualidade, excelência pela qualidade, e gestão estratégica pela qualidade são algumas das denominações encontradas na literatura contemporânea, 
utilizadas pelas empresas para designar um tipo de gestão orientada pelo objectivo de satisfazer ou exceder as expectativas dos clientes através da melhoria contínua.

Na perspectiva da gestão pela qualidade total, a filosofia de gestão é um processo dinâmico, de melhoria contínua, procurando melhorar a qualidade ao nível de todos os aspectos da organização, satisfazendo as expectativas dos clientes, bem como dos restantes grupos de interesse da organização.

Segundo Dean e Bowen (1994), a qualidade total não é apenas um conjunto de slogans e técnicas, mas um conjunto de princípios, práticas e técnicas, reforçados e integrados pelo objectivo de satisfazer os clientes. Nesta perspectiva, Hill e Wilkinson (1995) percebem a qualidade total como uma abordagem geral de gestão, estruturada por princípios básicos e por um conjunto de práticas e técnicas orientadas para a excelência. Para Dale, Van der Wiele e Van Iwaarden (2007) a gestão pela qualidade total materializa-se através de uma cooperação recíproca entre todos os elementos de uma organização e está associado aos processos da empresa que procura produzir bens que satisfaçam e excedam as necessidades e expectativas dos clientes.

Em síntese, a qualidade total combina elementos de teorias tradicionais de gestão com o princípio da satisfação dos clientes, através de acções de compromisso e pela procura e implementação de melhorias contínuas, projectando mudanças culturais na organização. Existe um forte consenso sobre a importância da gestão pela qualidade total para a competitividade de uma empresa. Para Slack, Chambers e Johnston (2002), a gestão pela qualidade total tem uma perspectiva aberta sobre a envolvente e dinâmica no que respeita às melhorias necessárias para que a empresa se torne mais competitiva.

A gestão pela qualidade total persegue, como uma característica fundamental da sua perspectiva, a satisfação dos seus clientes externos e internos, colocando uma ênfase especial na eficácia e definindo objectivos estratégicos que orientam a empresa para o mercado. A gestão pela qualidade total abrange toda a organização, com a direcção de topo especialmente comprometida e exercendo a função de liderança.

$\mathrm{Na}$ perspectiva da gestão pela qualidade total, todos os processos da organização, directos e indirectos, são visados. No que se refere aos métodos de trabalho, o mais relevante, dando por certo o estabelecimento de processos e de standards, é a definição de um sistema de gestão por objectivos. Para isso, parte-se da base que proporciona o conhecimento e a compreensão das necessidades e expectativas dos clientes, contando-se com a mobilização de toda organização em prol do cumprimento desses objectivos.

Para a gestão pela qualidade total, o desenvolvimento, a implicação e compromisso das pessoas, são consideradas como uma fonte de vantagem competitiva que permite promover a diferenciação perante as empresas concorrentes. A formação contínua, o desenvolvimento de 
carreiras, a motivação dos colaboradores, a delegação de poder e, sobretudo, a cooperação, o trabalho em equipa e o desenvolvimento organizacional, são os guias da gestão pela qualidade total nos recursos humanos da empresa. As competências, a adaptação e a coesão através de valores e crenças partilhadas, são mecanismos de coordenação extremamente importantes.

A área organizacional responsável pela qualidade encarrega-se de estabelecer objectivos e definir planos de acção relacionados com a qualidade. Assim, os responsáveis pela área da qualidade determinam a concepção e desenvolvimento do plano de formação e exercem uma actividade como consultores para outras áreas organizacionais. Todos os membros da equipa de direcção de topo são responsáveis por liderar a gestão pela qualidade total, garantindo o bom funcionamento do sistema.

A gestão pela qualidade total propõe uma acção de autocontrolo no âmbito da responsabilidade da acção dos diferentes colaboradores. A gestão pela qualidade total é exercida, sobretudo, através de uma acção de liderança, fomentando um estilo de gestão participativo. Deste modo, a gestão pela qualidade total reside nos múltiplos indivíduos e equipas que a gerem porque só assim se garantem os níveis de liderança e participação que implica esta forma de gestão.

\section{Liderança transformacional}

Diferentes estudos de investigação têm demonstrado que os líderes podem fazer uma diferença crítica no desempenho e ganhos de eficiência no funcionamento das organizações, e das equipas de trabalho (ZACCARO; KLIMOSKI, 2002; MORGESON, 2005). A liderança é, desta forma, um catalisador que transforma o potencial em realidade (NEWSTROM, 2008). Com efeito, os estudos de Salas, Sims e Burke (2005) incluem a liderança como um dos grandes cinco contributos para a eficiência de uma organização, através da performance das equipas de trabalho.

A investigação tem concluído que os líderes desempenham papéis importantes na modelação do trabalho em equipa efectivo, e no estabelecimento de princípios básicos, necessários ao funcionamento dos processos de trabalho (CASCIO; SHURYGAILO, 2003). Robbins (2007) define a liderança como a capacidade de influenciar um grupo para alcançar metas, considerando que nem todos os líderes são gestores e que nem todos os executivos são líderes. A liderança constitui-se como um processo de influenciar e apoiar outras pessoas para que elas trabalhem entusiasticamente na senda de determinados objectivos (NEWSTROM, 2008). Em suma, é consensual que a liderança é uma parte integral do trabalho nas organizações, contribuindo de forma decisiva para o seu desempenho.

Existem várias abordagens teóricas para o estudo da liderança, mas um dos modelos mais conhecidos e contemporâneos é a liderança transformacional/transaccional. Este modelo inscreve-se 
no âmbito das teorias neocarismáticas (ROBBINS, 2007). Estas teorias enfatizam o simbolismo, o apelo emocional e o extraordinário compromisso por parte dos seguidores. Entendida como o novo paradigma da liderança (BRYMAN, 1992), a distinção entre liderança transformacional e transaccional tem recebido uma enorme atenção por parte da investigação (DVIR et al, 2002).

De facto, Bass (1985) discerniu entre liderança transaccional e transformacional - que alguns consideram ofuscar a distinção entre liderança e gestão (POPPER; MAYSELESS; CASTELNOVO, 2000). No entanto, diversos autores (BARLING; SLATER; KELLOWAY, 2000; JUDGE; BONO, 2000) destacam exclusivamente o papel da liderança transformacional. Os líderes transformacionais inspiram os seus seguidores a transcender os seus próprios interesses em prol da organização, sendo capazes de causar um efeito profundo e extraordinário sobre os seus seguidores.

Estes líderes prestam atenção às preocupações e necessidades de desenvolvimento dos seus seguidores; são capazes de alterar a forma como os seus seguidores percepcionam as situações, e são capazes de promover entusiasmo, incitar e inspirar as pessoas a darem o máximo de si para alcançarem os objectivos de grupo (ROBBINS, 2007). A liderança transformacional sustenta-se numa forte identificação pessoal com o líder e numa partilha de visão futura. Trata-se de uma relação que envolve orgulho, respeito e fé no líder. Os líderes transformacionais delegam, transmitem coragem, inspiram os colaboradores e apoiam o seu desenvolvimento.

Estes líderes exercem influência idealizada e são admirados, respeitados e acreditados, reconhecem as necessidades dos seus seguidores, ganham créditos, partilham os riscos e são consistentes na sua conduta, dando ênfase à ética, princípios e valores. Por outro lado, através do carisma, o líder transformacional influencia os indivíduos a iniciar e a empreender um conjunto de acções/comportamentos de forma sustentada (NEWSTROM, 2008).

O líder transformacional tenta incutir nos seus seguidores a capacidade de questionar não apenas as visões estabelecidas, mas também as estabelecidas pelo próprio líder (AVOLIO; BASS, 1985). Os líderes transformacionais expressam expectativas de elevado desempenho, utilizando símbolos e uma linguagem provocatória capazes de inspirar os outros (NADLER; TUSHMAN, 1990). O comportamento deste tipo de líderes fomenta nos seguidores emoções fortes e de identificação.

A atitude inspiracional é outra característica dos líderes transformacionais: motivam os que o rodeiam e dão sentido ao trabalho; promovem o espírito individual e de equipa; encorajam os seus seguidores para estados de futuro visionários e atractivos; apelam à visão, ao uso de símbolos para focar os seguidores no esforço e na modelação de comportamentos apropriados; estimulam o esforço dos seus colaboradores; promovem a iniciativa, a criatividade e incentivam os colaboradores a colocarem questões, debaterem problemas e olharem as velhas situações de uma 
forma nova; e, não criticam de forma ridícula nem pública, aquando dos erros individuais. Os líderes transformacionais criam e comunicam uma visão para a organização (TICHY, 1989).

Esta visão conduz as pessoas além das suas capacidades e pensamentos actuais e encoraja-os no sentido de assumirem novos níveis de compromisso e entusiasmo, integrando crenças e valores, necessários à mudança de uma cultura organizacional orientada para performances de elevado rendimento (NEWSTROM, 2008). Assim, o comportamento deste tipo de líder aumenta a consciência sobre os problemas e influencia os seguidores a olhá-los sob uma nova perspectiva. Em períodos de maior turbulência e de mudança nas organizações, a relação que o líder estabelece com os seus subordinados assume particular destaque. De acordo com Bennis (2001), os líderes com maior capacidade de adaptação trabalham conjuntamente com os seus seguidores e aumentam a sua responsabilidade.

Os líderes transformacionais agem como mentores e treinadores, dão atenção às necessidades de cada indivíduo para que este se possa desenvolver e crescer. Os seguidores são sucessivamente desenvolvidos para níveis mais altos e de maior potencial. São criadas novas oportunidades de aprendizagem com um clima de suporte, de modo a promover o crescimento.

As diferenças individuais em termos de necessidades e desejos são reconhecidas. O líder suporta, encoraja e acompanha os seguidores. Os líderes transformacionais reconhecem que o seu legado não é simplesmente a mudança em si, mas uma organização que continuará a mudar. A sua tarefa crítica consiste em desenvolver a capacidade das pessoas para aprender a partir da experiência da mudança (double-loop learning - a forma como a informação é processada não reflecte apenas a informação actual - primeiro nível, mas também prepara os participantes para gerir mudanças futuras de modo mais eficaz - segundo nível).

Assim, estes indivíduos, desenvolvem a capacidade de se anteciparem aos problemas, prevenindo o aparecimento de situações adversas, desafiando as suas próprias convicções e os limites dos seus paradigmas (ARGYRIS, 1991). Diversos autores (TICHY; DEVANNA, 1986; KOUZES; POSNER, 1995; BASS, 1997) concluíram que a forma como os líderes transformacionais comunicam a visão e reconhecem as necessidades de mudança, leva os seguidores a conseguir mais do que o previamente esperado, alcançando resultados extraordinários.

A personalidade deste tipo de líderes caracteriza-se por determinados interesses e traços, como sejam, auto-confiança e determinação, e a sua experiência ao longo da vida é preponderante no seu desenvolvimento, nomeadamente pela diferenciação de traços individuais.

Segundo Bass (1997), os líderes transformacionais têm vontade de encorajar e olhar os velhos problemas de forma diferente. São pessoas que podem retirar e reforçar as suas energias, são donos do seu próprio destino e têm uma gama de talentos que os fazem atravessar com sucesso, tempos pouco favoráveis e de grande adversidade. 
Os líderes transformacionais têm a capacidade de promover e acompanhar os interesses pessoais dos seguidores, promover o comprometimento com os objectivos e missão do grupo/organização, motivando as pessoas a ir além dos seus próprios interesses em prol dos interesses do grupo/organização (DEN HARTOG; KOOPMAN, 2001).

$\mathrm{O}$ facto de os líderes transformacionais terem mais energia para impulsionar a mudança, não estando tão preocupados em manter o estado das coisas e o status, faz deles pessoas com padrões mais elevados de ousadia, com mais capacidades para introspecção e meditação. Em resumo, a liderança transformacional focaliza-se, segundo Bass e Avolio (1993), em motivar e inspirar os seguidores para um desempenho além das expectativas e incorpora quatro factores principais: 1) influência idealizada (ou carisma); 2) motivação inspiracional; 3) estimulação intelectual, e 4) consideração individualizada - Quadro 2.

Quadro 2 - Componentes da liderança transformacional

\begin{tabular}{l|l|l|l}
\multicolumn{5}{c}{ Componentes da Liderança Transformacional } \\
\hline \multicolumn{1}{c|}{ Influência Idealizada } & \multicolumn{1}{c|}{ Liderança Inspiracional } & \multicolumn{1}{c}{ Estimulação Intelectual } & \multicolumn{1}{c}{ Consideração Individualizada } \\
\hline $\begin{array}{l}\text { O líder adopta comportamentos que } \\
\text { activam fortes emoções nos seguidores, } \\
\text { suscitam a confiança e identificação } \\
\text { destes com ele, influenciam os seus } \\
\begin{array}{l}\text { ideais e os aspectos "maiores do que a } \\
\text { vida". }\end{array}\end{array}$ & $\begin{array}{l}\text { O líder comunica uma visão apelativa, } \\
\text { usa símbolos para fomentar o esforço dos } \\
\text { seguidores, actua como um modelo de } \\
\text { comportamentos, instila optimismo. }\end{array}$ & $\begin{array}{l}\text { O líder estimula os seguidores e tomada } \\
\text { de consciência dos problemas, dos seus } \\
\text { próprios pensamentos e imaginação. } \\
\text { Ajuda-os a reconhecer as suas próprias } \\
\text { crenças e valores. Fomenta-Ihes o } \\
\text { pensamento inovador/criativo. }\end{array}$ & $\begin{array}{l}\text { O líder atende às necessidades de } \\
\text { desenvolvimento dos seguidores, apoia- } \\
\text { os, encoraja-os, treina-os, tenta } \\
\text { desenvolver o seu potencial, fornece- } \\
\text { Ihes feedback, delega-lhes } \\
\text { responsabilidades. }\end{array}$ \\
\hline
\end{tabular}

Fonte: Adaptado de Cunha et al. (2007, p. 373)

Yukl (1999) e Bass et al. (2003), concluíram que a liderança transformacional prediz positivamente o desempenho, sendo que esta ideia é desenvolvida por House e Shamir (1993), tendo identificado quatro áreas de implicação directa da liderança transformacional no desempenho: 1) promover o valor intrínseco para o atingir das metas propostas; 2) a satisfação intrínseca dos seguidores da participação na missão do líder; 3) aumento do envolvimento através da visão do líder; e, 4) maior envolvimento dos seguidores.

O referencial ético e moral é um factor determinante na liderança transformacional, de tal forma que Bass e Steidlmeier (1999) introduzem a expressão de liderança autenticamente transformacional. Os líderes podem adoptar idênticos comportamentos transformacionais e até suscitar idênticas consequências, mas são os valores subjacentes que permitem distinguir quem é um autêntico líder transformacional (Quadro 3). 
Quadro 3 - Características do líder autenticamente transformacional

\begin{tabular}{l|l|l|l} 
Influência Idealizada & Liderança Inspiracional & Estimulação Intelectual & Consideração Individualizada \\
\hline $\begin{array}{l}\text { Orienta a sua necessidade de poder para } \\
\text { beneficio da organização e dos seus seguidores. }\end{array}$ & $\begin{array}{l}\text { Fomenta os valores da lealdade, justiça, } \\
\text { honestidade, direitos humanos, verdade, } \\
\text { franqueza, harmonia e trabalho sério. }\end{array}$ & $\begin{array}{l}\text { Ajuda os seguidores a questionarem as } \\
\text { assunções e a gerar soluções mais criativas. }\end{array}$ & $\begin{array}{l}\text { Proporciona apoio, mentoria e oportunidades de } \\
\text { crescimento aos colaboradores. }\end{array}$ \\
$\begin{array}{l}\text { Está disposto a fazer auto-sacrifícios. } \\
\begin{array}{l}\text { O seu objectivo não é ser idolatrado - mas obter } \\
\text { adesão dos seguidores a ideais. }\end{array}\end{array}$ & $\begin{array}{l}\text { Focaliza-se no desenvolvimento dos } \\
\text { colaboradores. } \\
\text { assunto. }\end{array}$ & $\begin{array}{l}\text { Procura desenvolver competências de liderança } \\
\text { nos seguidores. Ajuda-os a ser mais } \\
\text { competentes e bem sucedidos. }\end{array}$ \\
$\begin{array}{l}\text { Regra geral, é honesto, autêntico e confiável. } \\
\text { Promove políticas, procedimentos, processos e } \\
\text { cultura éticos. }\end{array}$ & $\begin{array}{l}\text { Está interior e exteriormente preocupado com oo do } \\
\text { bem do grupo, da organização ou da sociedade } \\
\text { como um todo. }\end{array}$ & $\begin{array}{l}\text { Tolera e fomenta a expressão de pontos de vista } \\
\text { diferentes dos seus próprios. }\end{array}$ & Para ele, as pessoas são um fim em si mesmo. \\
Apela à fraternidade. & & Trata cada seguidor com individuo.
\end{tabular}

Fonte: Adaptado de Rego e Cunha (2007, p. 241)

É com base nestas especificidades da liderança transformacional que a mesma se diferencia positivamente da liderança transaccional. Esta perspectiva é suportada por autores como Bass (1997) que considera que a liderança transformacional é mais efectiva que a liderança transaccional e que a liderança efectiva ao seu mais alto nível necessita de ir para além do simples binómio recompensa-castigo que tipifica a liderança transaccional.

Paralelamente, também Jung (2001) concluiu que as equipas lideradas face-a-face por um líder transformacional ultrapassam o desempenho das equipas conduzidas por um líder transaccional. A liderança transformacional está, por exemplo, mais fortemente correlacionada com indíces mais baixos de rotatividade, maior produtividade e maior satisfação dos indivíduos (LOWE; KROECK; SIVASUBRAMANIAM, 1996; JUDGE; BONO, 2000).

É ainda de referir a propósito dos acréscimos de eficiência de desempenho, associados à modalidade de liderança transformacional, outros dois estudos relevantes. No primeiro, num contexto de relações interpessoais face-a-face, a liderança transformacional alavancou o empowerment, a coesão de grupo e os princípios de funcionamento eficiente do grupo (JUNG; SOSIK, 2002). No segundo, Lim e Ployhart (2004) conduziram um trabalho com o objectivo de analisar a competição entre equipas e concluíram que a liderança transformacional estava fortemente relacionada com o desempenho de excelência das equipas.

Para além dos referidos trabalhos, foram realizadas meta-análises sobre a liderança transformacional e transaccional. Uma das meta-análises considerou que, embora ambos os estilos contribuam positivamente para o desempenho, os resultados gerados pela liderança transformacional eram significativamente mais relevantes (LOWE; KROECK; SIVASUBRAMANIAM, 1996). Uma meta-análise mais recente, de Judge e Piccolo (2004), considerou que a liderança transformacional era um estilo consistente de liderança. Em resumo, apesar dos estilos de liderança transaccional e transformacional estarem associados, a liderança transformacional tende a ser a mais efectiva (HAMBLEY; O’NEILL; KLINE, 2007). 


\section{A Liderança transformacional como factor de desenvolvimento na gestão pela qualidade}

total: criatividade, inovação, confiança e trabalho em equipa

As empresas modernas apostam nas competências e qualificações dos recursos humanos ao mesmo tempo que rompem com o modelo tradicional, ao adoptarem novos modelos de produção, onde praticam princípios como: a autonomia, a criatividade, a inovação, a confiança, o trabalho em equipa, a motivação, a polivalência, entre outros (KOVÁCS, 1993).

Os desempenhos nas organizações resultam de objectivos traçados pelos líderes e do nível de envolvimento das pessoas na sua realização (LAOHAVICHIEN; FREDENDALL; CANTRELL, 2009). Segundo Quinn (1996), nestas empresas a liderança é do tipo transformacional, centra-se nos recursos humanos e na inovação e define objectivos que visam motivar os indivíduos de forma a atingir a excelência e a eficácia do desempenho. Os líderes transformacionais definem objectivos de aprendizagem, mudança e elevado desempenho relacionados com a sustentabilidade da organização (LOPES; CAPRICHO, 2007).

A partir da bibliografia consultada, propõe-se um modelo que foca quatro das principais dimensões desenvolvidas pelo exercício de um estilo de liderança transformacional - representadas na Figura 3 - que contribuem para o alcance de resultados de excelência através de práticas de gestão pela qualidade total: 1) criatividade; 2) inovação; 3) confiança; e, 4) trabalho em equipa. Outras dimensões poderão, naturalmente, ser objecto de trabalhos de investigação futuros.

Figura 3 - O impacto da liderança transformacional no desenvolvimento da gestão pela qualidade total

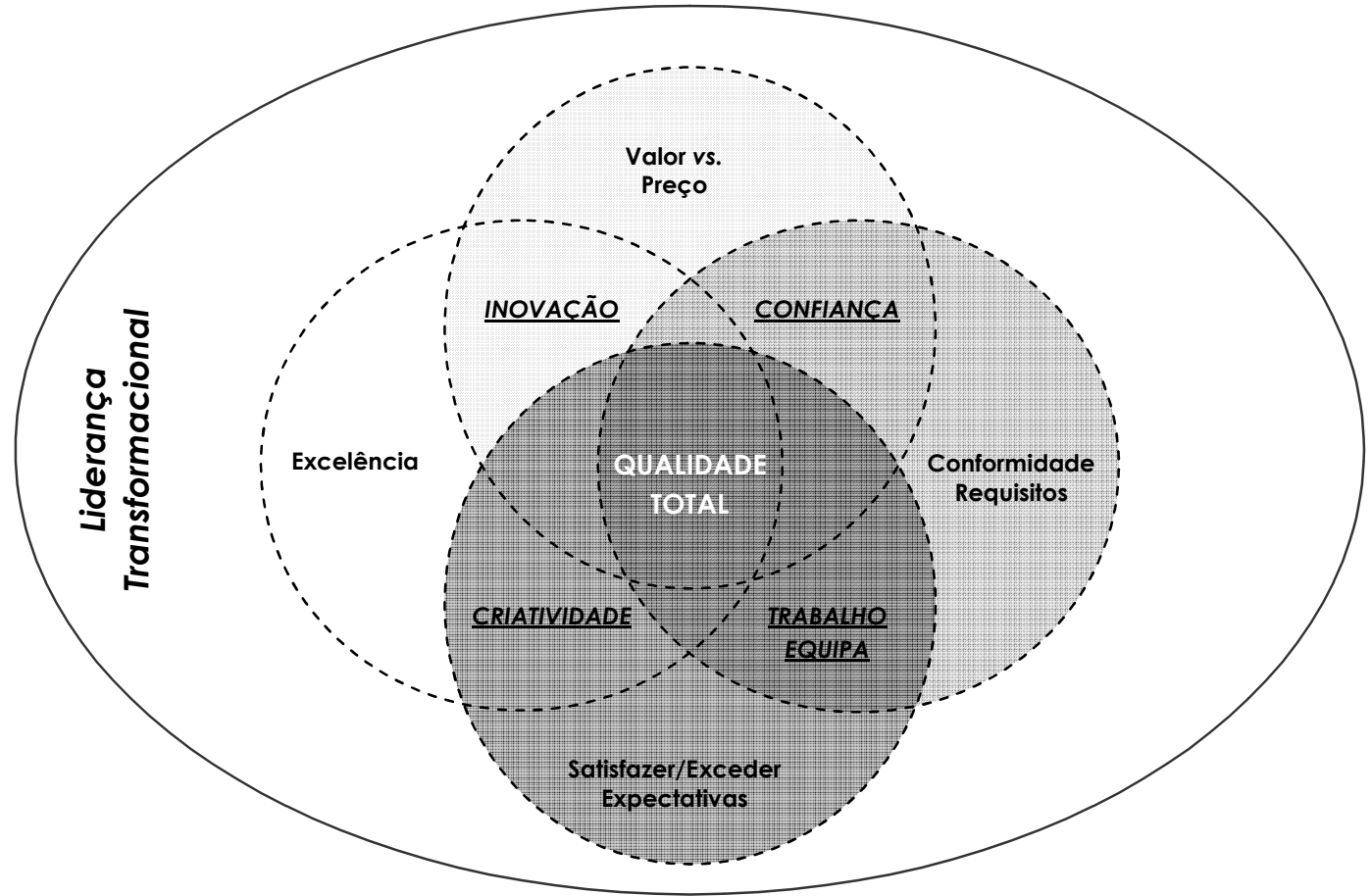

Fonte: Elaboração própria 
A qualidade total passa a centrar-se na cultura de empresa capaz de assegurar a satisfação e/ou exceder as expectativas dos clientes (PIRES, 2007), em conformidade com os requisitos estabelecidos, provocando no cliente um sentimento de excelência a um preço aceitável.

Mas será possível estabelecer alguma relação de casualidade entre as práticas de liderança transformacional - através do exercício de competências nas áreas da gestão, técnica e comportamental - e o alcance da qualidade total nas organizações? Para responder a esta questão central é explorada a relação conceptual entre a liderança transformacional e a gestão pela qualidade total - ao nível das dimensões da inovação, criatividade, confiança e trabalho em equipa apresentando-se proposições que carecem de validação empírica, e que se sugerem desenvolver em futuras investigações dentro desta área de conhecimento.

\subsection{A qualidade total é determinada pela criatividade}

A qualidade pode ser entendida como significando conformidade, consistência ou redução/ausência de variância (REEVES; BEDNAR, 1994). A qualidade implica a existência de um sistema de planeamento, rotinas e acções de verificação, controlando os processos dentro dos limites pré-estabelecidos. A gestão pela qualidade pode ser interpretada como um planeamento rigoroso orientado para a redução da incerteza, através do recurso a planos, programas ou sistemas de controlo estatístico.

No entanto, importa referir que a promoção da criatividade é um factor importante na gestão pela qualidade total (THOMPSON, 1998) através da qual os sujeitos colocam em prática as aprendizagens realizadas. A envolvente na empresa deve estimular, facilitar e valorizar o aparecimento de ideias criativas capazes de optimizar a afectação de recursos, a optimização de processos e de novas funcionalidades nos produtos - gerando valor acrescentado aos clientes. A qualidade deve criar as condições necessárias para o aparecimento de soluções criativas. Importa a este propósito referir que os factores individuais, culturais e estruturais podem facilitar ou inibir a criatividade (WILLIAMS; YANG, 1999).

Kanter (1984) indica uma lista de factores ambientais que contribuem para asfixiar a qualidade total: recursos e ferramentas limitadas; ordens de comando de cima para baixo; restrição de canais formais para a mudança; práticas não orçamentadas; actividade inovadora desfocada; reforço da cultura da inferioridade; comunicações laterais pobres; e, predominância das relações restritivas verticais. A criatividade ajuda à improvisação, importando sublinhar que improvisar não é desencadear uma falsa solução. "A improvisação implica a existência de um estrutura no quadro da qual se analisam e resolvem problemas não previstos e se apetrecha a organização com a 
capacidade de resposta às situações não antecipadas nem acomodadas pelo planeamento" (EDMONSON, 1995, p. 210).

A improvisação revela-se assim um conceito útil para a gestão pela qualidade total, pois combina a existência de uma estrutura e planeamento com a flexibilidade de resolver problemas ou situações não antecipáveis. Assim, o planeamento e a aprendizagem devem coexistir nas organizações (BREWS; HUNT, 1999) constituindo boas práticas de planeamento estratégico, particularmente em ambientes instáveis.

A cultura basicamente equaciona o padrão da partilha de valores, crenças e regras que regulam o comportamento, criando um conjunto de artefactos, estruturas, processos e símbolos (SCHEIN, 1992). A gestão pode não mudar a cultura de forma directa, mas pode intervir mudando as estruturas e os processos, fornecendo modelos e reforçando os estilos de comportamento preferidos. Assim, construir um clima criativo envolve o desenvolvimento sistemático de estruturas organizacionais, políticas e procedimentos de comunicação, sistemas de recompensa e de reconhecimento, políticas de formação, sistemas de contabilidade e de medida, e estratégia de combate (RICKARDS, 1997; LEONARD; SWAP, 1999; COOK, 1999).

A criatividade é relevante para catalizar a descoberta de novas possibilidades para resolver determinados problemas (CARAÇA, 2000), resultante, muitas vezes, de um esforço efectuado pela organização de forma mais ou menos continuada, para criar alterações úteis ao seu potencial económico e social (DRUCKER, 1993). Segundo Grant, Shani e Krishnan (1994), a qualidade total reconhece e valoriza uma das necessidades humanas fundamentais que é a necessidade de criar.

Proposição 1: As práticas de liderança transformacional contribuem positivamente para que a qualidade total resulte de um esforço organizacional orientado para a criatividade.

Concretamente, espera-se que as práticas de gestão associada à liderança transformacional estimule o desenvolvimento sistemático de medidas e acções de gestão capazes de recompensar o comportamento criativo e incentivar o seu aparecimento.

\subsection{A qualidade total resulta da capacidade de inovação}

A primeira forma de abordagem da qualidade tomava a inspecção como prática (BOUNDS, 1994). Deste modo, só a confrontação com os outputs do trabalho permitiria resolver falhas de qualidade. Assim, a qualidade seria uma questão de reacção. Uma outra perspectiva considerava que, mais do que detectar erros depois destes terem ocorrido, os gestores devem antecipar os erros prováveis e afastar as suas causas potenciais. Esta abordagem preventiva (GEVIRTZ, 1994), em vez 
de considerar a existência de um erro aceitável, define como objectivo os "zero" erros. Assim, a qualidade era percebida como a ausência de não qualidade. Sendo os erros detectados por prevenção ou por inspecção, o objectivo era o de evitar que ao consumidor chegassem produtos não conformes às especificações.

No entanto, outra forma de entender a qualidade, não negando a importância de prevenir o que se pode antecipar e de inspeccionar o que não pode ser previsto, toma o próprio processo e a sua melhoria como fonte de criação de valor para o cliente e, portanto, de qualidade pela via da diminuição de custos e aumento da qualidade.

Assim, o importante não é atingir o nível próximo da perfeição dos "zero" erros, mas também aprender e melhorar em permanência, de modo a que a qualidade não se transforme numa medida estática de validade interna sem expressão junto do consumidor, podendo condicionar a falta de capacidade da empresa acompanhar o dinamismo do mercado. Esta perspectiva ajuda a limitar os prejuízos da adopção e utilização de práticas incorrectas da qualidade (ex. moda), as quais poderão neutralizar os seus potenciais efeitos positivos, por força de rotinas geradas pelos procedimentos mantidos a bem da eficiência (WEICK; SUTCLIFFE; OBSTFELD, 1999) e não necessariamente da criação de valor para o cliente.

A aprendizagem informal e a experimentação explícita são importantes pois traduzem, muitas vezes, as vias pelas quais as organizações desenvolvem os seus saberes, ficando em condições de introduzirem inovações e crescerem nos mercados em que já estão instaladas ou entrarem em novos mercados. São as competências que definem o tipo de problemas que as empresas são capazes de resolver para os clientes efectivos e potenciais (CHANDLER, 1992; NONAKA; TAKEUCHI, 1995).

Nestes termos, é possível concluir que os produtos são manifestações de competências empresariais (PRAHALAD; HAMEL, 1990; LAWSON, 1999). As competências, potencialmente capazes de gerar inovação, são dinâmicas e geram novas rotinas capazes de subverterem os procedimentos instalados na organização (PAVITT, 2002). A mobilização e gestão do conhecimento dependem da mobilização a um nível muito mais elevado da participação na resolução de problemas inovadores e da criação das rotinas na organização (GARVIN, 1993).

A inovação pode ser representada como um ciclo de aprendizagem, envolvendo um processo de experimentação, experiência, reflexão e consolidação. Para gerir este processo, importa criar as condições para que as oportunidades de aprendizagem possam emergir e ser exploradas. Apresenta-se assim como um factor crítico, desenvolver a competência para gerir este ciclo de aprendizagem, como por exemplo, no desenvolvimento de novos produtos ou na execução de novos processos tecnológicos (BOWEN, 1994). 
Os inovadores de sucesso revêem e vão tomando decisões, internalizando rotinas específicas para gerir o desafio da inovação. Torna-se por isso relevante promover o funcionamento de um ciclo de aprendizagem para aquisição e absorção do conhecimento tecnológico, mas também de um ciclo relativo à aprendizagem e melhoria do próprio processo de inovação (ARGYRIS, 1970).

Inovar supõe a capacidade de interpretar o mercado, de compreender os desejos e necessidades dos clientes actuais e potenciais, para fornecer produtos e/ou serviços de excelente qualidade a um preço justo.

Proposição 2: As práticas de liderança transformacional contribuem positivamente para que a qualidade total resulte de um esforço organizacional orientado para a inovação.

Concretamente, é expectável que as práticas de gestão associadas à liderança transformacional tomem o próprio produto/processo e a sua melhoria como fonte de criação de valor para o cliente e, portanto, de qualidade pela via da diminuição de custos e/ou aumento da qualidade, incentivando a organização a aprender e a melhorar continuamente, evidenciada pelo número de sugestões apresentadas e soluções implementadas.

\subsection{A qualidade total é determinada pela confiança}

A confiança é um tema central de gestão contemporânea (KRAMER; TYLER, 1996). Inicialmente, a gestão pela qualidade baseava-se apenas no recurso a formas de organização e controlo orientadas para a estandardização e para a aplicação de normas que tornassem a confiança um elemento desnecessário e dispensável. Assim, uma das condições necessárias para a implementação da gestão pela qualidade refere-se à existência de um conjunto de normas e mecanismos de controlo capazes de assegurar a menor variabilidade possível.

Neste contexto, a variância constitui o alvo da atenção da gestão. Neste caso, mais do que confiar na racionalidade e na capacidade de decisão dos colaboradores, criando um contexto em que a subjectividade das decisões pessoais seja eliminada e substituída pela racionalidade do próprio sistema.

Por outro lado, uma das condições necessárias para a implementação da gestão pela qualidade refere-se à existência de um ambiente de confiança ancorado num propósito comum (THOMPSON, 1998).

Empregados receosos terão comportamentos defensivos e não apresentarão o género de compromisso necessário com a organização para a colocação em prática dos princípios da qualidade total. A constituição de equipas coesas só é possível se existir confiança entre os seus membros, 
potenciando níveis elevados de autonomia necessários ao seu bom desempenho (NECK; MANZ, 1996).

Assim, os mecanismos de controlo dão lugar à confiança e à pressão do grupo no sentido do respeito pelo objectivo comum da equipa e da própria organização. A confiança na equipa, e a crença na organização e nos seus objectivos, são um requisito básico para alavancar a qualidade total.

Quando através do processo comunicacional, as partes estabelecem uma relação de negociação, que considere os interesses de ambos, esta culmina com a formação do contrato psicológico, estabelecendo-se ou reforçando-se uma relação de confiança (TURNLEY; FELDMAN, 1999).

Importa relevar a importância que a qualidade dos contratos psicológicos estabelecidos tem sobre o rendimento dos seus sujeitos. Uma vez estabelecida uma relação de confiança entre líderes e seguidores, reforçam-se as condições necessárias conducentes ao estabelecimento de compromissos, através do processo de negociação, definição e aceitação de objectivos (GIBSON; IVANCEVITH; DONNELLY, 1998).

A confiança e a credibilidade modulam o acesso do líder ao conhecimento e à cooperação (ZAND, 1997). Demonstrar confiança na outra pessoa gera reciprocidade. Os líderes eficazes vão consolidando a confiança aos poucos e encorajam os seguidores a responder da mesma maneira. Nas organizações, a confiança deve existir na justa medida em que facilita o trabalho conjunto (HACKMAN; WAGEMAN, 1995), a qual decorre da existência de compromissos e consensos mínimos. A gestão pela qualidade total não dispensa a existência de uma estrutura normalizada, nem de níveis mínimos de confiança.

Para que a liderança seja eficaz, há todo um trabalho de coordenação, compromisso e negociação que deve assentar no respeito e confiança, no exemplo e na responsabilização, conciliando interesses e vontades divergentes, fomentando o empowerment e criando um espírito de cooperação e entreajuda que conduza ao desenvolvimento de equipas motivadas e auto-geridas, que apostam na qualidade e na aprendizagem permanente (LOPES; CAPRICHO, 2007).

Proposição 3: As práticas de liderança transformacional contribuem positivamente para que a qualidade total resulte do desenvolvimento de relações de confiança.

Concretamente, é expectável que as práticas de gestão associadas à liderança transformacional, estejam directamente relacionadas com o desenvolvimento de relações de confiança capazes de aumentar os níveis de compromisso (orientados para objectivos de elevado rendimento), partilha de conhecimentos e cooperação entre os sujeitos. 


\subsection{A qualidade total é determinada pelo trabalho em equipa}

Aparentemente parece que a qualidade implica a existência de níveis elevados de controlo. A importância da consistência e da fiabilidade dos produtos/serviços faz do controlo um imperativo para a gestão da qualidade. A importância do controlo é um dado explícito na literatura de qualidade. A variância é a causa principal dos problemas da qualidade, tendo por isso de ser controlada (HACKMAN; WAGEMAN, 1995). À gestão compete melhorar a compreensão das causas da variância, bem como explorar a informação contida na variação (DEMING, 1986).

Por outro lado, a qualidade requer a participação dos indivíduos (como caixa de sugestões) e de equipas (por exemplo, círculos de qualidade). Indivíduos e equipas tendem a apresentar melhores resultados quando lhes é dada a possibilidade de autonomia ou controlo sobre o seu próprio trabalho. A investigação em Psicologia do Trabalho demonstra que elevados níveis de autonomia constitui uma das características das funções motivadoras (HACKMAN; OLDHAM, 1980). Assim, é expectável que os colaboradores sejam participantes activos. Neste contexto, compreende-se que as técnicas mais usadas, no que se refere à gestão pela qualidade (HACKMAN; WAGEMAN, 1995), sejam a formação de equipas de trabalho para resolução de problemas, seguida da formação. A constituição de círculos de qualidade e as reuniões para a qualidade entre gestores e colaboradores são exemplos que ilustram a importância da participação e do envolvimento de todos os colaboradores numa organização.

A gestão pela qualidade total implica níveis elevados de autonomia e controlo. Nos sistemas de controlo são definidos apenas alguns elementos (como prazos, responsabilidades e objectivos), sendo os restantes atribuídos à autonomia da equipa. Neste tipo de estruturas (equipas) existe um pequeno número de grandes regras (BROWN; EISENHARDT, 1997). A função dos líderes e gestores consiste em zelar pelo respeito e cumprimento do conjunto de regras estabelecidas na organização. A equipa de trabalho dispõe de um espaço de controlo e autonomia crucial para o cumprimento das suas funções.

Por melhores que se apresentem os sistemas de qualidade, quanto à definição e desenvolvimento de produtos e processos, a sua probabilidade de sucesso está fortemente condicionada pela estrutura e enquadramento da organização.

Muitas vezes, é necessário criar e/ou recriar as estruturas e processos organizacionais que permitam o bom funcionamento da organização, através da gestão pela qualidade total. Em geral, quanto menos programadas e mais incertas forem as tarefas maior será a necessidade de flexibilizar a estrutura das relações (THOMPSON, 1967). 
Quanto maior for a incerteza e a complexidade do meio envolvente, maior será a necessidade de ter estruturas flexíveis e processos adaptados (MILES; SNOW, 1978; LAWRENCE; DYER, 1983). O desafio chave para a gestão pela qualidade total consiste em adaptar a estrutura à variabilidade das circunstâncias.

Outra visão da estrutura considera que ela é um artefacto das crenças, das pessoas e do modo como se comportam: se houver uma boa adaptação, a estrutura facilitará e reforçará o comportamento orientado para a qualidade total; se contradisser as crenças, restringindo, por exemplo, a comunicação pressionando a hierarquia, então é provável que se possa comportar como um travão à qualidade total.

Importa referir, que este conceito de organização não se limita a um grupo de indivíduos organizados sob uma forma específica para alcançar um objectivo comum. A empresa é também percebida como uma célula que estabelece elos de ligação com outras organizações. Assim, o trabalho em rede representa uma solução eficiente para o problema da escassez dos recursos afectos à qualidade total. A investigação sobre o trabalho em equipa inter-organizacional indicia que existem oito processos chave que precisam de ser geridos, e devem ser tratados como se constituíssem uma forma particular da organização (BESSANT; TSEKOURAS, 2001): criação de redes; tomadas de decisão; resolução de conflitos; tratamento da informação; captação de conhecimento; motivação/empenho; partilha de riscos/benefícios; e, integração.

O modelo de "Excelência" da EFQM, por exemplo, refere que a liderança deve ser efectuada em todos os níveis da organização, e resultar de um trabalho de equipa conjunto, para adaptar a organização ao ambiente externo e que permita reconhecer, compreender e satisfazer todas as necessidades e expectativas dos diferentes stakeholders.

Proposição 4: As práticas de liderança transformacional contribuem positivamente para que a qualidade total resulte do funcionamento das equipas de trabalho.

Concretamente, é expectável que as práticas de gestão associadas à liderança transformacional, estejam directamente relacionadas com o desenvolvimento do trabalho em equipa, promovendo elevados níveis de participação, autonomia e controlo, garantindo, em simultâneo, o respeito e cumprimento pelo conjunto de regras organizacionais que balizam o funcionamento das equipas de trabalho orientadas para a qualidade total. 


\section{A liderança transformacional: uma alavanca para a qualidade total}

Para além da importância central da liderança, as organizações com níveis de performance elevados caracterizam-se por apresentarem outros elementos, cujo denominador comum é ajudar a desenvolver as capacidades dos seus colaboradores, os seus conhecimentos, as suas motivações e flexibilidade. Entre estes elementos, incluem-se: a visão, a missão, a estratégia e as metas; as crenças e os valores; as práticas de gestão; a estrutura organizacional; as práticas de trabalho; os processos operacionais e procedimentos funcionais; e, os sistemas de recursos humanos. Ainda que as organizações com elevados níveis de performance possam evidenciar diferentes práticas, todas elas assentam no princípio de que as pessoas são o activo mais importante e mais competitivo.

Em síntese, a organização orientada para a qualidade total implica mais do que um conjunto de processos e uma estrutura. É um conjunto integrado de componentes que se inter-relacionam para gerar e reforçar um ambiente favorável à qualidade total. As referidas componentes das organizações orientadas para a qualidade total estão relacionadas directamente com o sucesso empresarial, podendo ser estimuladas pelo exercício de práticas de gestão associadas a um estilo de liderança transformacional (Quadro 4).

Quadro 4 - O impacto da liderança transformacional no desenvolvimento da gestão pela qualidade total

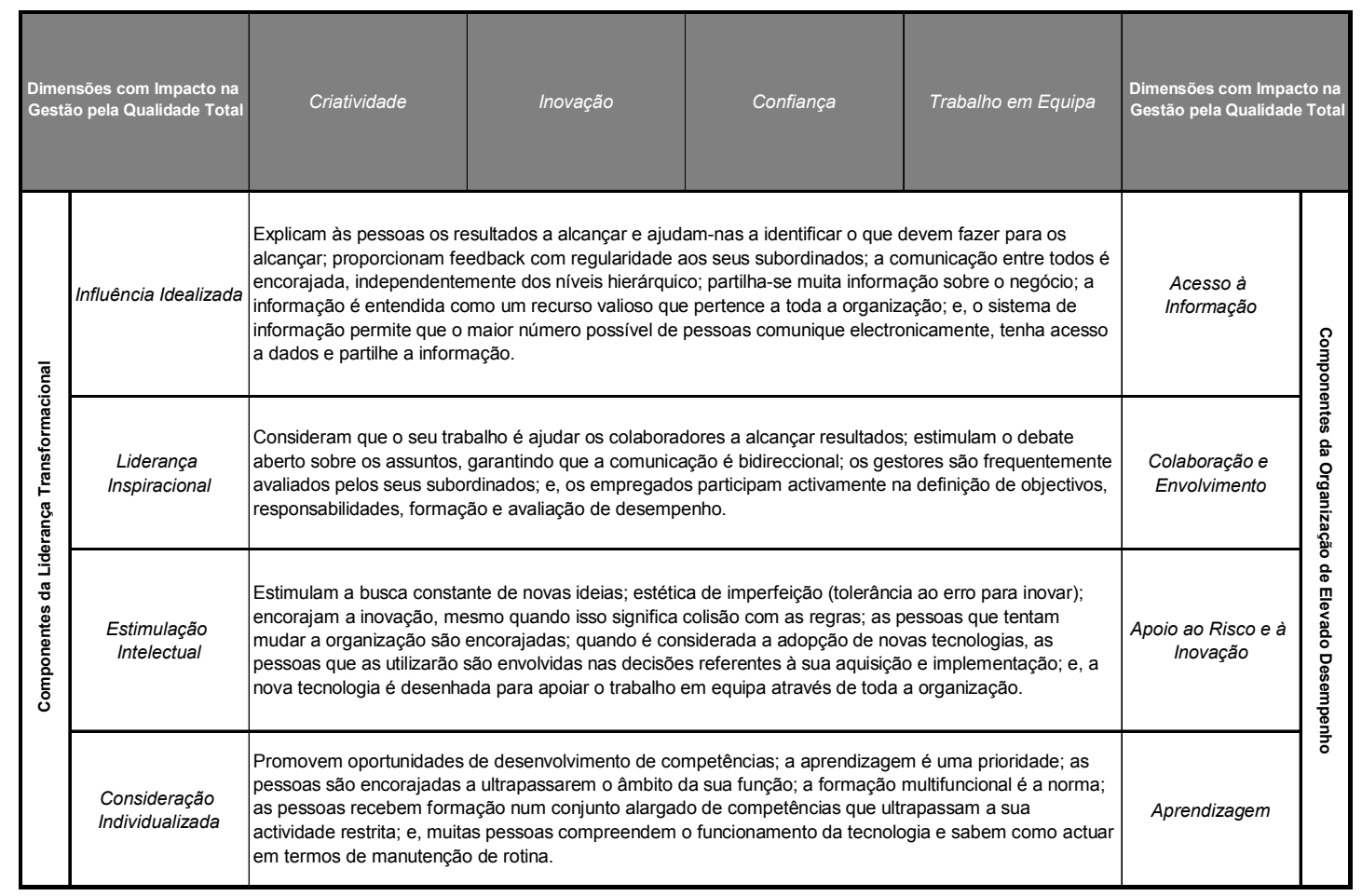

Fonte: Elaboração própria

No mundo de hoje, onde os trabalhadores são instruídos e autoconscientes, não se pode limitar o seu papel à periferia da problemática da qualidade total, reduzindo-os a meras "extensões 
de máquinas", como era proposto pelo paradigma taylorista/fordista (ISHIKAWA, 1995). O método de Taylor não reconhece as aptidões dos indivíduos, ignora a humanidade e trata os sujeitos como máquinas, tornando-se o trabalho desinteressante e insatisfatório. Sob tais condições não é possível obter produtos com qualidade e clientes satisfeitos (LOPES; CAPRICHO, 2007).

\section{Considerações finais}

Ao reflectir sobre os novos desafios da gestão e na forma como as organizações devem ser geridas, não pode-se ignorar a importância de antecipar cenários de mudança para definir a sua estratégia futura que devem integrar domínios da gestão, tais como a gestão do conhecimento, gestão da mudança, gestão do risco, gestão da inovação, gestão pela qualidade total, entre outros, que devem ser liderados com qualidade e eficácia, valorizando e desenvolvendo o Capital Humano.

A qualidade total é uma responsabilidade de todos, em geral, e da gestão de topo em particular. Os esforços necessários à implementação de uma filosofia assente na qualidade total devem ter origem no topo da organização. O processo de implementação da qualidade deve ser executado de forma descendente (top down). A implementação de programas de qualidade decorre de uma conjugação entre uma clara condução e direcção por parte da gestão de topo, e um incentivo no sentido da participação, do trabalho em equipa e da colaboração interfuncional.

Em contextos de mercado cada vez mais competitivos, orientados por exigências acentuadas de performance nas organizações em função de resultados expectáveis difíceis de alcançar, importa aos agentes das organizações com maior responsabilidade, não apenas compreender o fenómeno da liderança e os seus impactos, mas sobretudo, perceber de que forma se podem dinamizar práticas de liderança, orientando os indivíduos para performances de elevado rendimento.

Esta acentuada pressão do meio sobre a organização, impõe mudanças. Neste sentido, para promover um processo de mudança positiva, os líderes devem potenciar as capacidades de renovação, e de rejuvenescimento das organizações, criando ambientes organizacionais que potenciem respostas ajustadas à envolvente (REGO; CUNHA, 2007).

Neste sentido, os líderes ao criarem novos contextos (novos papeis, novas responsabilidades, novas tecnologias, e novas interacções), promovem novos comportamentos e atitudes nos seus colaboradores (DOISE; DESCHAMPS; MUGNY, 1980). Liderar a mudança, é uma das mais importantes e difíceis tarefas de liderança.

É necessária uma liderança eficaz para revitalizar uma organização e facilitar a adaptação ao ambiente em mudança, sob pena de estas não lhes sobreviverem (YUKL, 1998). As organizações necessitam de pessoas empenhadas, comprometidas, dispostas a "irem mais além" e a adoptarem comportamentos espontâneos, inovadores e de cidadania. Essa postura tende a emergir, quando os 
seus membros se sentem satisfeitos e justiçados, têm confiança na organização e nos seus decisores, e sentem que a organização se preocupa com o seu bem-estar (ROBINSON, 1996).

As organizações necessitam de melhores cidadãos organizacionais, embora as condições vigentes tendam a minar os alicerces em que a cidadania se desenvolve (contratos psicológicos, confiança, sentido psicológico de comunidade de trabalho, apoio organizacional percepcionado, justiça e satisfação). Neste contexto, a liderança transformacional emerge como um factor susceptível de criar melhores condições, necessárias para ultrapassar as anunciadas adversidades, através do estabelecimento de contratos psicológicos equilibrados e sustentados.

Alguma pesquisa académica tem apoiado a ideia de que a liderança da gestão de topo é necessária para a melhoria da qualidade (BENSON; SARAPH; SCHROEDER, 1991; FLYNN; SCHROEDER; SAKAKIBARA， 1995; SCHROEDER; LINDERMAN; ZHANG, 2005; LAOHAVICHIEN; FREDENDALL; CANTRELL, 2009).

Mas que estilo de liderança é mais efectivo? E de que modo pode a liderança não só iniciar os esforços de qualidade mas também assegurá-los de uma forma sustentável? O modelo de Baldrige apoia o conceito de liderança visionária como um dos seus princípios chave. A liderança visionária está associada à liderança transformacional e opõem-se à liderança transaccional (BASS 1985; KUHNERT; LEWIS 1987; LAOHAVICHIEN; FREDENDALL; CANTRELL, 2009).

Existem outras temáticas emergentes relacionadas com a liderança que constituem oportunidades de investigação na área da qualidade, tais como a teoria da inteligência emocional (EVANS; LINDSAY, 2005). A confiança é outro tema emergente na liderança e consiste na expectativa positiva de que o outro não agirá de forma oportunista (ROBBINS, 2007). Os líderes podem ajudar a criar um clima de confiança que promova a colaboração inter-funcional (WEBBER, 2002).

Outra área importante de investigação é o desenvolvimento da liderança e o planeamento da sucessão, e a sua influência na qualidade. Para um modelo que se pretende transformador de relações de trabalho, existe um vazio de referencial teórico e de investigações empíricas que permitam uma avaliação sistemática dos seus efeitos. A construção de um modelo que defina as relações de casualidade entre as variáveis sociais e comportamentais é um dos desafios que se impõe a quem pretende avaliar os efeitos da gestão pela qualidade total no quotidiano do trabalho, e da liderança na gestão pela qualidade total.

A mudança de um estilo de gestão baseado em atitudes de controlo e comando para um estilo caracterizado por atitudes de liderança transformacional, o encorajamento e apoio às iniciativas dos indivíduos, gera um impacto positivo no modelo de gestão pela qualidade total (LAOHAVICHIEN; FREDENDALL; CANTRELL, 2009). As hipóteses de investigação 
apresentadas devem ser amplamente testadas, com particular incidência na relação - positiva e significativa - entre inovação, criatividade, confiança e trabalho em equipa.

Neste sentido, torna-se absolutamente necessário desenvolver projectos de investigação que coloquem à prova as proposições apresentadas, ajudando a confirmar e a robustecer os seus pressupostos, para que o modelo possa ser generalizado.

O novo paradigma de gestão aponta para as pessoas como a verdadeira fonte de criação de riqueza. A necessidade de uma nova filosofia de gestão impõe-se para questionar o sistema organizativo tradicional e os velhos valores culturais, para transformar o contexto de trabalho num verdadeiro "ambiente formativo" e para considerar os recursos humanos e o ambiente onde estes se desenvolvem como "factores críticos de sucesso" das organizações. "É deles e dos seus conhecimentos que depende a qualidade dos produtos e dos serviços das organizações e, consequentemente, a produtividade e a competitividade a longo prazo" (LOPES; CAPRICHO, 2007, p. 58).

\begin{abstract}
Several research studies have led to the identification of leadership as a potential catalyst for total quality management. Moreover, empirical studies have shown, consistently, a significant and positive relationship between transformational leadership and performance indicators in the work. A structured system of leadership must be based on clear values and organizational principles that support the processes of decision making and to guide and inspire the organization, affecting all employees, by way of standards of excellence. Thus, and to promote a culture of excellence geared towards total quality requires a strong coordination and convergence of management practices across all organizational actors. In this context, it is crucial that the top management of the organization to establish a set of values and organizational principles able to establish a way forward, and may benchmark the behavior of its members, directing action to organizational quality standards. Among the researchers and experts is unanimous recognition that it is for top management to lead the movement for quality. In this sense, it is expected that leaders define the mission and organizational strategy, establish values and management principles inspiring the best management practices geared towards total quality. This paper explores the conceptual relationship between transformational leadership and total quality management - in terms of dimensions of innovation, creativity, trust and teamwork - featuring original propositions that could guide future research in this field.
\end{abstract}

Keywords: total quality management; transformational leadership; creativity; innovation; trust; teamwork.

\title{
Referências
}

ANTÓNIO, N.; TEIXEIRA, A. Gestão da qualidade: de Deming ao modelo de excelência da EFQM. Lisboa: Edições Sílabo, 2007.

ARGYRIS, C. Organizational Llearning. Reading: Addison-Wesley, 1970.

ARGYRIS, C. Teaching smart people how to learn, Harvard Business Review, Maio, pp. 99-109, 1991. cross ${ }^{\text {ref }}$

AVOLIO, B.; BASS, B. Transformational leadership, charisma and beyond. Journal of Management, vol. 9, pp. 14$28,1985$.

BARLING, J.; SLATER, F.; KELLOWAY, E. Transformational leadership and emotional intelligence: an exploratory study", Leadership and Organization Development Journal, Vol. 21, nº 3, pp. 157-161, 2000. 
BASS, B. Leadership and performance beyond expectations, New York, Free Press, 1985.

BASS, B. Does the transactional-transformational leadership paradigm transcend organizational and national boundaries?, American Psychologist, vol. 52, pp. 130-139, 1997.

cross ${ }^{\text {ref }}$

BASS, B. e AVOLIO, B. Transformational leadership: a response to critiques", Leadership theory and research: perspectives and directions, pp. 49-79, New York: Academic Press, 1993.

BASS, B.; AVOLIO, B.; JUNG, D.; BERSON, Y. Predicting unit performance by accessing transformational and transactional leadership, Journal of Applied Psychology, vol. 88, n², pp. 207-218, 2003.

cross'

BASS, B.; STEIDLMEIER, P. Ethics, character, and authentic transformational leadership behaviour, Leadership Quarterly, vol. 10, pp. 181-217, 1999.

cross ${ }^{\text {ref }}$

BENNIS, W. Leading in unnerving times, MITS Sloan Management Review, vol. 42, pp. 97-102, 2001.

BENSON, P.;SARAPH, J.; SCHROEDER, R. The effects of organizational context on quality management: an empirical investigation, Management Science, vol. 37, $\mathrm{n}^{\circ}$ 9, pp. 1107-1124, 1991.

cross ${ }^{\text {ref }}$

BESSANT, J.; TSEKOURAS, G. Developing learning networks, A. I. and Society, vol. 15, nº 2, pp. 82-98, 2001. cross ${ }^{\text {ref }}$

BOUNDS, G. Beyond total quality management: toward the emerging paradigm, New York: McGraw-Hill, 1994.

BOWEN, H. Regaining the lead in manufacturing, Harvard Business Review, Set./Out., pp. 108-144, 1994.

BREWS,P.; HUNT, M. Learning to plan planning to learn: resolving the planning school/learning scholl debate, Strategic Management Journal, vol. 20, pp. 889-913, 1999.

BROWN, S.; EISENHARDT, K. The art of continuous change: linking complexity theory and time-paced evolution in relentlessly shifting organizations, Administrative Science Quarterly, vol. 42, pp. 1-34, 1997.

cross ${ }^{\text {ref }}$

BRYMAN, A. Charisma and leadership in organizations. London: Sage, 1992.

CARAÇA, A. Globalização, inovação e qualidade, Revista Opção Q, vol. 17, pp. 12-38, 2000.

CARAVATTA, M. Conducting an organizational self-assessment using the 1997 Baldridge award criteria, Quality Progress, vol. 30,n ${ }^{\circ}$ 10, pp. 87-91, 1997.

CASCIO, W.; SHURYGAILO, S. E-leadership and virtual teams, Organizational Dynamics, vol. 31, n 4, pp. 362376, 2003.

cross ${ }^{\text {ref }}$

CHANDLER, A. Organizational capabilities and the economic history of the industrial enterprise, Journal of Economic Perspectives, Summer, pp. 79-100, 1992.

COOK, P. Best oractice creativity. Aldershot: Gower, 1999.

CORRIGAN, J. Is ISO 9000 the path to TQM?”, Quality Progress, vol. 27, n 5, pp. 33-36, 1994.

CUNHA, M.; REGO, A.; CUNHA, R.; CABRAL-CARDOSO, C. Manual de comportamento organizacional e gestão. Lisboa: Editora RH, 2007.

DALE, B.; VAN DER WIELE, T.; VAN IWAARDEN, J. Managing quality. Oxford: Blackwell Publishing, 2007. 
DEAN, J.; BOWEN, D. Management theory and total quality: improving research and practice through theory development, Academy of Management Review, vol. 19, n 3, pp. 392-418, 1994.

cross ${ }^{\text {ref }}$

DEMING, W. Out of the crisis. Cambridge: MIT Center for Advanced Engineering Study, 1986.

DEN HARTOG, D.; KOOPMAN, P. (2001). Leadership in organizations. In: ANDERSON, N.; ONES, D.; SINANGIL, H.; VISWESVARAN, C. (Eds.), Handbook of industrial, work and organizational psychology, Vol. 2, pp. 166-187, London: Sage.

DOISE, W.; DESCHAMPS, J.; MUGNY, G. Psicologia social experimental. Lisboa: Moraes, 1980.

DRUKER, P. Sociedade pós-capitalista. Lisboa: Difusão Cultural, 1993.

DVIR, T.; EDEN, D.; AVOLIO, B.; SHAMIR, B. Impact of transformational leadership on follower development and performance: a field experiment, Academy of Management Journal, vol. 45, n 4, pp. 735-744, 2002.

cross'

EASTON, G. The 1993 state of U.S. total quality management: a Baldridge examiner`s perspective, California Management Review, vol. 35, n 3, pp. 32-54, 1993.

EDEN, D.; GELLER, D.; GEWIRTZ, H.; GORDON-TERNER, A.; LIBERMAN, R.; PASS, M.; SALOMON, Y.; SEGEV, I.; SHALIT, M. (2000). Implanting Pygmalion leadership style through workshop training: seven field experiments, Leadership Quarterly, Outubro, pp. 49-54, 2000.

EDMONSON, A. Learning from mistakes is easier said than done: group and organizational influences on the detection and correction of human error, Journal of Applied Behavioural Science, vol. 32, n 1, pp. 5-28, 1995.

EVANS, J.; LINDSAY, W. The management and control of quality. South-Western: Mason, 2005.

FLYNN, B.; SCHROEDER, R.; SAKAKIBARA, S. The impact of quality management practices on performance and competitive advantage, Decision Sciences, vol. 26, n 5, pp. 659-692, 1995.

cross'

GARVIN, D. Building a learning organization, Harvard Business Review, Jul/Ago., pp. 78-91, 1993.

GEVIRTZ, C. Developing new products with TQM. New York: McGraw-Hill, 1994.

GIBSON, J.; IVANCEVITH, J.; DONNELLY, J. Organizations: behaviour, structure, processes. Homewood: Irwin, 1998.

GRANT, R.; SHANI, R.; KRISHNAN, R. TQM's challenge to management theory and practice, Sloan Management Review, Winter, pp. 25-35, 1994.

HACKMAN, J.; OLDHAM, G. Work redesign. Reading: Addison-Wesley, 1980.

HACKMAN, J.; WAGEMAN, R. Total quality management empirical, conceptual, and practical issues, Administrative Science Quarterly, vol. 40, pp. 309-342, 1995.

cross ${ }^{\text {ref }}$

HAMBLEY, L.; O’NEILL, T.; KLINE, T. Virtual team leadership: the effects of leadership style and communication medium on team interaction styles and outcomes, Organizational Behavior and Human Decision Processes, vol. 103, pp. 1-20, 2007.

HILL, S. e WILKINSON, A. In search of TQM, Employee Relations, vol. 17, n 3, pp. 8-25, 1995.

cross'

HOUSE, R.; SHAMIR, B. Toward the integration of transformational, charismatic, and visionary theories. In: CHEMERS, M.; AYAMAN, R. (Eds.), Leadership theory and research: perspectives and directions, pp. 81-107. New York: Academic Press, 1993.

ISHIKAWA, K. What is total quality control?, Rio de Janeiro: Editora Campus, 1995. 
JUDGE, T.; BONO, J. Five-factor model of personality and transformational leadership, Journal of Applied Psychology, vol. 85, pp. 751-765, 2000.

cross ${ }^{\text {ref }}$

JUDGE, T.; PICCOLO, R. Transformational and transactional leadership: a meta-analytic test of their relative validity, Journal of Applied Psychology, vol. 89, pp. 755-768, 2004.

cross ${ }^{\text {ref }}$

JUNG, D. Transformational and transactional leadership and their effects on creativity in groups, Creativity Research Journal, vol. 13, $\mathrm{n}^{\circ}$ 2, pp. 185-195, 2001.

cross'ref

JUNG, D.; SOSIK, J. Transformational leadership in work groups: the role of empowerment, cohesiveness, and collective-efficacy on perceived group performance, Small Group Research, vol. 33, n 3, pp. 313-336, 2002.

crossef

JURAN, J. Juran on leadership for quality: an executive handbook. New York: Free Press, 1989.

KANTER, R. The change masters. London: Unwin, 1984.

KOUZES, J.; POSNER, B. The leadership challenge: how to keep getting extraordinary things done in organizations. San Francisco: Josey-Bass, 1995.

KRAMER, R.; TYLER, T. Trust in organizations. London: Sage Publications, 1996.

KOVÁCS, I. Tendências de transformação tecnológica e organizacional nas empresas: a emergência de novos sistemas produtivos, Revista Economia e Sociedade, vol. 1, Novembro, pp. 83-93, 1993.

KUHNERT, K.; LEWIS, P. Transactional and transformational leadership: a constructive/developmental analysis, Academy of Management Review, vol. 12, n 4, pp. 648-657, 1987.

cross ${ }^{\text {ref }}$

LAOHAVICHIEN, T.; FREDENDALL, L.; CANTRELL, R. The effects of transformational and transactional leadership on quality improvement, The Quality Management Journal, vol. 16, n 2, pp. 7-24, 2009.

LAWRENCE, P.; DYER, P. Renewing American industy. New York: Free Press, 1983.

LAWSON, C. Towards a competence theory of the region, Cambridge Journal of Economics, vol. 23, pp. 151-166, 1999.

cross ref

LEONARD, D.; SWAP, W. When sparks fly: igniting creativity in groups. Boston: Harvard Business School Press, 1999.

LIM, B.; PLOYHART, R. Transformational leadership: relations to the five-factor model and team performance in typical and maximum contexts, Journal of Applied Psychology, Vol. 89, n 4, pp. 610-621, 2004.

cross ${ }^{\text {ref }}$

LIVINGSTON, J. Pygmalion in management, Harvard Business Review, vol. 47, pp. 81-89, 1969.

LOPES, A.; CAPRICHO, L. Manual de gestão de qualidade. Lisboa: Editora RH, 2007.

LOWE, K.; KROECK, K.; SIVASUBRAMANIAM, N. Effectiveness correlates of transformational and transactional leadership: a meta-analytic review of the MLQ literature, Leadership Quarterly, vol. 7, n 3, pp. 385-425, 1996.

cross ${ }^{\text {ref }}$

MILES, R.; SNOW, C. Organizational strategy, structure and process. New York: McGraw-Hill, 1978. 
MORGESON, F. The external leadership of self-managing teams: intervening in the context of novel and disruptive events, Journal of Applied Psychology, vol. 90, n 3, pp. 497-508, 2005.

cross ${ }^{\text {ref }}$

NADLER, D.; TUSHMAN, M. Beyond the charismatic leader: leadership and organizational change, California Management Review, Winter, pp. 77-97, 1990.

NECK, C.; MANZ, C. Total leadership quality: integrating employee self-leadership and total quality management, Advances in the Management of Organizational Quality, vol. 10, n 1, pp. 39-77, 1996.

NEWSTROM, J. Comportamento organizacional: o comportamento humano no trabalho. São Paulo: McGraw-Hill, 2008 .

NONAKA, I.; TAKEUCHI, H. The knowledge creating company. New York: Oxford University Press, 1995.

PAVITT, K. Innovating routines in the business firm: what corporate tasks should they be accomplishing?, Industrial and Corporate Change, Vol. 11, $\mathrm{n}^{\circ}$ 1, pp. 117-133, 2002.

cross ${ }^{\text {ref }}$

PIRES, A. Qualidade: sistemas de gestão da qualidade. Lisboa: Edições Sílabo, 2007.

PFEFFER, J. Competitive advantage through people. Boston: Harvard Business School Press, 1994.

POPPER, M.; MAYSELESS, O.; CASTELNOVO, O. Transformational leadership and attachment, Leadership Quarterly, vol. 11, pp. 267-289, 2000.

crossef

PRAHALAD, C.; HAMEL, G. The core competence of the corporation, Harvard Business Review, Maio/Junho, pp. 79-91, 1990.

QUINN, R. Deep change. California: First Edition, 1996.

REEVES, C.; BEDNAR, D. Defining quality: alternatives and implications, Academy of Management Review, vol. 19, $\mathrm{n}^{\circ} 3$, pp. 419-445, 1994.

cross ${ }^{\text {ref }}$

REGO, A.; CUNHA, M. A essência da liderança: mudança, resultados e integridade. Lisboa: Editora RH, 2007.

RICKARDS, T. Creativity and problem solving at work. Aldershot: Gower, 1997.

ROBBINS, S. Comportamento organizacional. São Paulo: Pearson Prentice Hall, 2007.

ROBINSON, S. Trust and breach of the psychological contract, Administrative Science Quarterly, vol. 41, pp. 574599, 1996.

ROSENTHAL, R.; JACOBSON, L. Pygmalion in the classroom: teacher expectation and pupil's intellectual development. New York: Holt, Rinehart \& Winston, 1968.

SALAS, E.; SIMS, D.; BURKE, C. Is there a "big five” in teamwork?”, Small Group Research, vol. 36, pp. 555-599, 2005.

cross ${ }^{\text {ref }}$

SCHEIN, E. Organizational culture and leadership. San Francisco: Jossey-Bass, 1992.

SCHROEDER, R.; LINDERMAN, K.; ZHANG, D. Evolution of quality: first fifty issues of production and operations management, Production and Operations Management, vol. 14, n 4, pp. 468-481, 2005.

SLACK, N.; CHAMBERS, S.; JOHNSTON, R. Administração da produção. São Paulo: Atlas, 2002.

TICHY, N. GE's Crottonville: a staging ground for corporate revolution, Academy for Management Executive, Maio, pp. 99-106, 1989. 
TICHY, N.; DEVANNA, M. The transformational leader. New York: John Wiley \& Sons, 1986.

THOMPSON, J. Organizations in action. New York: McGraw-Hill, 1967.

THOMPSON, K. Confronting the paradoxes in a total quality environment, Organizational Dynamics, Winter, pp. $62-$ 74,1998

cross'ef

TONK, H. Integrating ISO 9001:2000 and the Baldridge criteria, Quality Progress, vol. 33, n 8, pp. 51-55, 2000.

TURNLEY, W.; FELDMAN, D. The impact of psychological contract violations on exit, voice, loyalty and neglect, Human Relations, vol. 52, n 7 , pp. 895-922, 1999.

cross ref

VOKURKA, R.; STANDING, G.; BRAZEAL, J. A comparative analysis of national and regional quality awards, Quality Progress, vol. 33, $\mathrm{n}^{\circ}$ 8, pp. 41-49, 2000.

WALDMAN, D. A theoretical consideration of leadership and total quality management, Leadership Quarterly, vol. 4, pp. 65-80, 1993.

cross ${ }^{\text {ref }}$

WEBBER, S. Leadership and trust facilitating cross-functional team success, Journal of Management Development, vol. $23, n^{\circ} 3$, pp. 201-214, 2002.

cross ${ }^{\text {ref }}$

WEICK, K.; SUTCLIFFE, K.; OBSTFELD, D. Organizing for high reliability: processes of collective mindfulness. In: Sutton, R.; Staw, B. (Eds.), Research in organizational behaviour, pp. 81-123. Greenwich: Jay Press, 1999.

WHITE, S.; LOCKE, E. Problems with the Pygmalion effect and some proposed solutions, Leadership Quarterly, vol. 11, pp. 389-415, 2000.

cross ${ }^{\text {ref }}$

WILLIAMS, W.; YANG, L. Organizational creativity. In: Sternberg, R. (Eds.), Handbook of creativity, pp. $373-391$. New York: Oxford University Press, 1999.

cross ${ }^{\text {ref }}$

YUKL, G. Leadership in organizations. Englewood Cliffs: Prentice-Hall, 1998.

YUKL, G. An evaluative essay on current conceptions of effective leadership, European Journal of Work and Organizational Psychology, vol. 8, pp. 33-48, 1999.

cross ${ }^{\text {eef }}$

ZACCARO, S.; KLIMOSKI, R. The interface of leadership and team processes, Group and Organization Management, vol. 27, pp. 4-13, 2002.

cross ${ }^{\text {ref }}$

ZAND, D. The leadership trial: knowledge, trust, and power. New York: Oxford Press, 1997.

\section{Dados dos autores:}

Nome completo: Rui Correia, MsC.

Filiação institucional: Universidade da Beira Interior (UBI)

Departamento: Gestão e Economia

Função ou cargo ocupado: Doutorando em Gestão

Endereço completo para correspondência: Estrada do Sineiro, pólo IV, Covilhã, Portugal, CEP: 
$6200-209$

Telefones para contato: (351) 275319600

e-mail: rfcorreia.sa@gmail.com

Nome completo: Emerson Wagner Mainardes, MsC.

Filiação institucional: Universidade da Beira Interior (UBI)

Departamento: Gestão e Economia - Núcleo de Estudos em Ciências Empresariais (NECE)

Função ou cargo ocupado: Doutorando em Gestão e Investigador Convidado do NECE

Endereço completo para correspondência: Loteamento Ribeira de Flandres, lote 16, R/C DTO, Covilhã, Portugal, CEP: 6200-802

Telefones para contato: (351) 275334404 / 968567657

e-mail: emerson.wm@sapo.pt

Nome completo: Luis Lourenço, PhD.

Filiação institucional: Universidade da Beira Interior (UBI)

Departamento: Gestão e Economia - Núcleo de Estudos em Ciências Empresariais (NECE)

Função ou cargo ocupado: Professor Associado e Investigador do NECE

Endereço completo para correspondência: Estrada do Sineiro, pólo IV, Covilhã, Portugal, CEP: 6200-209

Telefones para contato: (351) 275319600

e-mail: lourenco@ubi.pt 